Article

\title{
Children's Literature in Critical Contexts of Displacement: Exploring the Value of Hope
}

\author{
Julie E. McAdam ${ }^{1, *} \mathbb{C}$, Susanne Abou Ghaida ${ }^{1}$, Evelyn Arizpe ${ }^{1}$, Lavinia Hirsu ${ }^{1}$ \\ and Yasmine Motawy ${ }^{2}$ \\ 1 School of Education, University of Glasgow, Glasgow G3 6NH, UK; \\ s.abou-ghaida.1@research.gla.ac.uk (S.A.G.); evelyn.arizpe@glasgow.ac.uk (E.A.); \\ lavinia.hirsu@glasgow.ac.uk (L.H.) \\ 2 Department of Rhetoric and Composition, American University in Cairo, Cairo 11835, Egypt; \\ ymotawy@aucegypt.edu \\ * Correspondence: julie.e.mcadam@glasgow.ac.uk
}

Received: 7 October 2020; Accepted: 5 December 2020; Published: 16 December 2020

\begin{abstract}
The article builds upon work carried out through a Children's Literature in Critical Contexts of Displacement (CLCCD) network funded by the Arts and Humanities Research Council-Global Challenges Research Fund. The network brought together academics as well as government and non-governmental organisations with expertise in children's literature, migration, and education who were actively working in Egypt and Mexico. They collaboratively designed workshops that examined the use of children's literature as a cultural tool for post-crisis interventions that could contribute to creating a safe space for children and their families to reimagine and restore their self and group identities. This article begins by unravelling the concept of hope, arguing for a critical understanding of hope for transformative use within contexts of flux. Using a critical content analysis approach, five picturebooks used by Egyptian and Mexican mediators were analysed in order to develop an understanding of how critical hope developed within the texts. The emerging themes have been expanded into a set of guiding questions that will enable mediators and educators to use children's literature in contexts of displacement or precarity.
\end{abstract}

Keywords: children's literature; contexts of displacement; precarity; mediators; critical hope; critical content analysis

\section{Introduction}

Human mobility is a complex and diverse phenomenon, often linked to acute events such as political instability, conflict, economic crises, or environmental disasters [1] (p. 2). One outcome of such events in recent times has been the forcible displacement of around 35.6 million children across the globe [2], necessitating interventions from governments and international agencies. The two contexts that will be addressed in this article, Egypt and Mexico, are both countries that have served as 'migration corridors' for transiting populations, including children, moving from Syria and sub-Saharan Africa towards Europe and from Latin America to the United States, respectively. In both cases, the hesitant policy responses have resulted in 'a proliferation of informal practices that override formal regulations' [3] (p. 9). On the ground, this has meant community groups, often supported by NGOs, working to provide basic services and create safe space for children and families to re-imagine and restore their self and group identities, preserve their cultural heritage and establish cohesive relationships with host populations.

The article builds upon work carried out through a Children's Literature in Critical Contexts of Displacement (CLCCD) network funded by the Arts and Humanities Research Council-Global Challenges 
Research Fund (AHRC-GCRF). The network brought together academics as well as government and non-governmental organisations with expertise in children's literature, migration, and education who were actively working in Egypt and Mexico. As the network developed, they were joined by individuals and institutions from surrounding countries. The aim of the network was to examine and exchange knowledge on how to support formal and informal interventions with displaced children and families. The focus was on researching two main issues: the potential of children's literature to facilitate the creation of safe spaces where tensions and traumas connected to displacement could be resolved; and the role played by mediators in selecting and using children's literature. We drew on work by psychologists working in the area of trauma, who defined five intervention principles to direct post-disaster responses. These were to promote: a sense of safety, calming, a sense of self and community efficacy, connectedness and hope [4]. Our previous research on picturebooks found that they had the potential to enrich, comfort, and provide children, families and communities with a sense of future direction and hope through (1) the themes present, and (2) the responses they generated [5].

Hope is a ubiquitously used term, with no one stable meaning. Therefore, we will begin by examining how it is understood by children's literature scholars and educators, before considering how hope may be conceptualised more critically as a means to direct and prefigure ways of being that allow human flourishing. Using critical content analysis methods [6], picturebooks selected by Egyptian and Mexican mediators were analysed in order to establish a set of generated themes [7]. These themes can be used in global contexts by mediators and educators working with children in circumstances of precarity or instability.

\section{Literature Review}

\section{Children's Literature, Hope, and Pedagogical Implications}

Children's literature is viewed as a valuable resource for any society, with Nilsen and Donelson [8] (p. 3) describing books as gifts given from the community to young people, in the hope that books will help them succeed in their journeys into adulthood. Beauvais built on this notion, arguing that children's literature is 'inherently hopeful because it implies a child-reader who is future bound' [9] (p. 47). This future-minded orientation of books was also suggested by Bloch [10], who referred to literature as a source of a 'utopian impulse', with Halpin clarifying that the utopian dimension signals that such books fuel the imagination and allow readers to enter into 'thought experiments' about the future [11] (p. 54). In these instances, hope is rooted in humanity's incompleteness and a future search for 'what is not yet' [12] (p. 8). These scholars are framing children's literature as a source of hope that invites children to engage in future-orientated reflections about their selves or their environments. For anyone working with children, this means acknowledging that children's literature offers more than a source for making meaning of their background stories and life experiences. It also has the potential to generate a desire to explore, question, and learn how to become something more than we are now, ontologically linking hope to education $[12,13]$.

This ontological link, which is grounded in the notion that education and hope are co-constitutive, also requires educators and mediators to 'take care not to experience it (hope) in a mistaken form, allowing it to slip towards hopelessness and despair, since these cause inaction and fear' [12] (p. 9). Webb [14], Duncan-Andrade [15], and Beauvais [9] all counselled against false or directionless hopes located in an impossible future giving rise to an unfounded optimism that all will be well, located in shallow narratives of equal opportunities and individual success. Hope is far more than a happy ending. For it to have traction and momentum, any hopeful ending needs to be encountered alongside an element of realism [16] that includes an examination of the root causes and possible solutions to injustice. This calls for a more nuanced and radical understanding of what is meant by hope and the ways in which it can be evoked and directed towards transformation.

Critical pedagogues have sought to imbue hope with direction through suggesting ways in which it can be manifested in practice as 'material hope', drawing on resources, networks, and knowledge [15] 
(p. 186). Webb suggested we talk of 'utopian hope', acknowledging that humanity is capable of self-determination through an ongoing process of critiquing present injustices in order to imagine future possibilities [13] (p. 332). The utopian aspect is vital if the deferred hopes of children, families, and communities caught up in displacement are to be infused with agency and transformative ability [17] (p. 228). This aligns with Sargent's view that educators should engage with utopian children's literature because it provides 'a safe place for experimentation to learn and grow and work out who you are' [18] (p.233). His use of the word 'safe' should not be read as indicative of the topics or themes present within the literature, nor does his view apply only to utopian/dystopian literature. Rather, what can be utopian about children's literature are the possibilities it provides for dialogue, analysis, and imagination. It provides tools to pre-figure ways of being in the world that encourage and orientate our thoughts and actions.

Within educational settings much has been said about the value of children's literature, including its potential to provide sources of 'understanding about the human condition' [19] (p. 245); reduce prejudice and educate about diversity [20]; promote cultural understanding [21]; reflect life as we know it [22]; develop empathy $[23,24]$; and confront global issues of injustice [25]. Through a close reading of various texts, these children's literature scholars have uncovered themes that could potentially provide young readers and their communities supportive ways to frame and reframe their feelings and understandings of the world. This latent value of children's literature can be realised when readers and viewers are guided and directed in their responses by parents, friends, mediators, and teachers. This article draws upon critical content analysis methods to examine children's literature selected by mediators working in contexts of displacement in order to identify emerging themes and the ways in which they represent opportunities for collective agency through hope [26].

\section{Workshops and Project Process}

Building on the premise that children's literature could be used as a vehicle for evoking directed hope, the network facilitated the running of a series of workshops for Egyptian and Mexican mediators in 2017 and 2018. The workshops aimed to develop the mediators' capacity to select and use children's literature when working with displaced children and their families. To guide and initiate our discussions with mediators regarding the potential of picturebooks, we shared Rudine Sims Bishop's metaphors of mirrors, windows, and doors [27]. Understanding texts as mirrors acknowledges that through the characters, contexts, and their actions, children and their communities should engage with literature where they can see representations of themselves, providing a way to ground one's identity within one's own culture [28]. The metaphor of windows highlights the need to select texts that provide insights into the lives of other social and cultural groups and pose alternative worlds and options to a reader. They become an opportunity for the reader to juxtapose his or her or their own values and beliefs with those in the text. The process of looking in the mirror and out the window leads the reader/viewer to metaphorically cross the threshold of the door, reframe their thinking, and possibly engage in future-orientated action [19]. We shared an extended range of text engagement strategies, using art, drama, and photography, allowing the mediators time to explore the metaphors and activities they could use when working with children.

During the workshop, we drew on our experience as children's literature scholars to share a range of texts, many of which we have written about or used in previous research projects. With each workshop we ran, we were asked further questions on how to select appropriate texts. This suggested that while the metaphors provided a helpful way to begin examining texts, further support was needed. In January 2019, three of the authors, Susanne, Julie, and Yasmine were preparing for a second round of workshops in Egypt. The group understood the challenges in sourcing quality texts and wanted to purchase a selection of texts from the 50th International Cairo Book Fair in order to make up 'book bags', which would be taken away and immediately used by the workshop attendees. Before engaging in text selection, they sat and interviewed each other about their diverse academic traditions and how these influenced their decision-making processes when selecting texts. 
The points that emerged could be synthesised into three key elements: personal affective responses, an appreciation of the book as an aesthetic object (content and form), and expectations of the ways in which children would respond as readers/viewers of the book. The group used these elements to create an extended guide to text selection with reflective questions and shared it the following day with 40 new workshop participants. The 'text selection guide' is available on the CLCCD website (https://childslitspaces.com/toolkit/) along with suggested picturebooks and guides on multimodal response strategies. To date, the guide has been accessed by a range of global mediators and children's literature students to make confident text selections and reach decisions on the value a selected text could bring to a context. The network website and social media channels provided a means for mediators to provide feedback and share stories of practice. Through this feedback we noted patterns emerging in the texts chosen by mediators across multiple contexts. We wondered what was happening within these texts that drew multiple mediators time and time again towards particular multilayered picturebooks. They included two wordless books, Footpath Flowers (originally published in Canada as Sidewalk Flowers) and The Arrival (published with Spanish and Arabic titles with the latter version reading from right to left and the direction of the images reversed). Three books originally written in the main languages spoken in Egypt (Arabic) and Mexico (Spanish) also proved to be popular 'go-to texts' with mediators wanting to meet the social and emotional needs of displaced children and their families. These books have been written and illustrated by authors and illustrators from Australia, Canada, Colombia, Lebanon, Peru, and Syria (See Table 1 for titles and author/illustrator information).

Table 1. List of picturebooks.

Details
$\begin{aligned} & \text { Amgad fi Akoun ... aw la } \\ & \text { Akoun (Amgad in To Be... } \\ & \text { or Not To Be) } \\ & \text { Written and illustrated } \\ & \text { by Alaa Mortada (2017) } \\ & \text { Al Balsam Publishing } \\ & \text { House, Cairo, Egypt. }\end{aligned}$




\section{Methodology}

Critical content analysis is a process of questioning the social structures embedded within a text through the lens of a critical theory and with an objective of illuminating imbalances of power. However, as Short noted, [29] critical content analysis is not simply an investigation into negative representations but equally involves the examination of texts that offer positive portrayals or resist harmful mainstream narratives. In fact, we would argue that the picturebooks covered in this article are all texts that promote safety, calm, a sense of self, and community connectedness [4] as opposed to strife, exclusion, and isolation.

In analysing the focus texts, our starting point was the aforementioned guide to text selection, which allowed us 'to think within, through and beyond the texts' [6] (p. 4). We had framed many of our 'guide to text selection' questions around human flourishing, and, more specifically, we paid attention to our own emotional responses to the book, the authors and their intentions, the aesthetic and stylistic aspects of the books, the use of space, relationships and power, the representation and agency of the characters. In the case of these five books, we also directly addressed the extent to which they may be considered hopeful books, drawing upon our knowledge of how children and mediators had received and used the books. Throughout the process of analysis, we paid attention to the role played by both the visual and verbal elements of the text. Guided by this framework, we produced a close reading of these books, from which certain themes began to emerge (presented in Section 5 within Table 2).

Table 2. Sources of hope within the picturebooks.

\begin{tabular}{ll}
\hline \multicolumn{1}{c}{ Cultural, Conceptual, and Physical Tools } & \multicolumn{1}{c}{ Book } \\
\hline Silence and communication & Amma Osha, Eloisa and the Bugs \\
\hline Safe space for experimentation & Amgad \\
\hline Forging new relationships, friendships, sociality & Eloisa and the Bugs, The Arrival \\
\hline $\begin{array}{l}\text { Kindness, engagement, and exchange (physical touch, } \\
\text { gift-giving, conviviality, sharing stories, offering help) }\end{array}$ & Eloisa and the Bugs, Footpath Flowers, The Arrival \\
\hline Memory-keeping (the role of artefacts) & Eloisa and the Bugs, The Arrival \\
\hline Community, inclusion, and belonging & Amma Osha \\
\hline Acceptance of difference & Amma Osha, Eloisa and the Bugs \\
\hline Awareness of self/Identity formation & Amgad \\
\hline Future orientations & Amgad, Footpath Flowers, The Arrival \\
\hline
\end{tabular}

We then returned to our extended understanding of utopian hope as discussed above, in order to answer our original query about why the mediators were continually drawn to these texts. We noted that these books shared a series of themes that we called resources of hope (c.f. [30]). These were cultural tools, social networks, and processes utilised by the characters in order for some form of change to be realised, be it resisting oppressive forces, nurturing or protecting a sense of agency, and engaging in transformation, with future possibilities suggested or realised. These resources of hope are explained in Section 6 below.

\section{Analysis and Emerging Themes}

Working with children and adults in difficult or precarious conditions does not necessitate the selection of 'heavy' books. In this instance, only two of the books, The Arrival and Eloisa y los Bichos, deal directly with migration. In addition, humour plays a central role in the two Arabic books and in no way undermines their effectiveness. There are also light-hearted moments in The Arrival and Eloisa y Los Bichos, while Footpath Flowers presents a compassionate story of a girl's walk in the city. 


\subsection{Amgad fi Akoun ... aw la Akoun (Amgad in To Be ... or Not to Be)}

Amgad fi Akoun ... aw la Akoun (henceforth referred to as Amgad) narrates, in humorous rhyme and bright pastel watercolour illustrations, the attempts of the eleven-year-old character, Amgad, to decide on a vocation. It is written and illustrated by the young Syrian author, Alaa Mortada, who has herself experienced displacement following the unrest in Syria, settling first in Egypt and later in the United States.

At the beginning of the narrative, a preamble addresses the readers directly, explaining that Amgad is a very ordinary boy who is distinguished only by his persistence in seeking an answer to the question 'what shall I be when I grow up?' The book goes on to describe Amgad's attempts at eight different career paths, with disastrous and hilarious results. The book ends with four blank sheets headed by two question prompts that invite the readers to sketch and describe their own dreams for the future. While the story is set in the Helwan area of Cairo, the illustrations contain few, if any, identifiably 'Arab' details typically inserted into illustrations of globalised spaces and people in local picturebooks. The text, on the other hand, engages intertextually and playfully with elements of Arab literary heritage and popular beliefs.

The quest for a vocation is initiated by Amgad rather than prompted by an adult, and the experimentation takes the protagonist outside the realm of traditional careers (doctor, engineer) encouraged by middle-class professionals. Furthermore, the depiction of the parents as patient and somewhat indulgent supporters of Amgad's self-discovery is a positive representation of the kind of consistent adult care that builds stability and fosters resilience in children, particularly those experiencing internal turmoil. The story presents a child assuming agency in times of uncertainty to execute his imaginative forays into a utopian future, thus reframing uncertainty as a source of possibilities rather than a harbinger of continued instability.

Although teenagers from families in crisis may feel deep guilt about not being financially able to enter into a form of experimentation similar to Amgad's, the book grants children permission to engage in a world of hopeful possibilities and 'defocalises' the present moment of crisis. The use of a book so steeped in 'normalcy', rather than one that provides a mirror to the situation of the child in crisis, is not necessarily tone-deaf or exclusionary. Rather, it provides a sliding door into a potentially halted aspect of childhood that can be reclaimed by children in flux. This is done by making them aware of the innate imaginative toolbox they possess and how it may be drawn from to create personal stability in the future, as well as resilience in the present moment.

The book was used in a reading at the 2019 Cairo Book Fair, and the mediation involved encouraging the children to sketch out their possible futures. To invite the children into an open discussion, they were asked: 'What choices would you make if you were Amgad? Why does he make these choices? Is the narrator right: does Amgad have no special talents?' Children who may not share Amgad's sheltered life may respond in surprising ways to his choices, dismissing them as frivolous or implausible, or offering alternate ideas of being entrepreneurial rather than vocational pursuits that can be executed immediately and do not require long and costly training.

\subsection{Al-Amma Osha (Auntie Osha)}

Al-Amma Osha also presents a light and humorous story, and its rich, multilayered illustrations provide much space for diverse interpretations. The book contains a number of visual cues that set the story in the United Arab Emirates. The landscape includes a mosque and several iconic Dubai landmarks (Burj Khaleefa and Burj el-Arab), while the main character and other women in the story are veiled and modestly dressed. It is worth noting that veiled women are often underrepresented in Arabic children's books, and, in this sense, the book can act as a powerful mirror for some readers.

The central character is Al-Amma Osha (Osha is a diminutive of the name Aysha), a loquacious old woman. She is accompanied by a fox who is never mentioned in the text. The illustrator uses small triangular newspaper cuttings to convey Amma Osha's speech, which spills out from her mouth causing disruption and chaos wherever she goes. The book derives much humour from juxtaposing her blithe 
unawareness of the effects of her talk with the panicked reactions of those around her. 'Stop talking, Amma Osha,' the members of her community repeatedly request. One day, she does as she is told and disappears from view along with her talk. While the community are relieved at first to have some peace and quiet, the townspeople eventually miss Amma Osha and wonder where she has gone. They pay her a visit at her home to find her despondent and ill in her bed. To lift her spirits, they begin to talk and sing until she is revived and resumes talking. In a delightful end to the story, we see Amma Osha deciding to rest for the remainder of the day as she has a lot of talking to do the next day. In the final spread, we see her cutting out triangles from a newspaper as she prepares for the coming day.

The book has the potential to raise questions about tolerance, coexistence, and their complexities at both the communal and interpersonal levels. Amma Osha's talk is clearly presented as excessive and disruptive, but the book is subversive in avoiding a didactic closure. While she is initially silenced to an extent that renders her physically unwell, the book avoids further violence by not requiring her to change or be reformed, as is often the case in children's books.

The most salient power relationship in the book is that between Amma Osha, as someone who deviates from norms of temperance, and the rest of the community, who end up silencing and excluding her. These dynamics might echo the experiences of those rejected or driven out from their communities for a number of reasons, mainly their inability or unwillingness to conform to societal norms of proper and good behaviour. There is a clear shift in Amma Osha's sense of confidence and ease in the world. While at the start of the book, she is at home wherever she goes in her town, she is later confined to her physical home. Fortunately, Amma Osha's estrangement is only temporary, and her community takes steps to embrace and accept her on her own terms. Amma Osha's reclaiming of her voice, untarnished and uncompromised, which occurs at the initiative of her community, can be a very powerful message. The hopeful turn in Al-Amma Osha is the outcome of the return to a state of community harmony, a soothing balm for those whose life circumstances have separated them from their communities or where social and political conditions have compromised the integrity and dignity of communities.

We have used this book with children, educators and picturebooks mediators in different contexts. One observation was how the visual cues in the book lend themselves to very different interpretations based on the cultural background of the observer [31]. We have also used the book to get participants in multilingual groups to contemplate, present, and (hopefully) appreciate their own multilingual diversity, capabilities, and resources. Triangles were cut out, inspired by the ones coming out of Amma Osha's mouth, and participants wrote on them the things they spoke about, the languages they used, and the means they used to communicate. This exercise afforded new arrival children a space for self-expression and exchange, a chance to better know each other and to find common channels of communication.

\subsection{Eloisa y Los Bichos (Eloisa and the Bugs)}

The title and illustrations of Eloisa y los Bichos play on a saying in Spanish, 'sentirse como bicho raro', which means literally 'to feeling like the odd bug', or more figuratively to be 'the odd one out'. A young girl, Eloisa, arrives with her father in a city where all the inhabitants appear to be human-sized insects and other creatures. Despite their appearance, these creatures are carrying out everyday human activities.

In the beginning, the father and daughter are lost and lonely, and Eloisa finds it hard to understand what everyone is saying, to keep up or play with the others at school. Slowly, however, both Eloise and her father begin to interact with some of the creatures around them, and with time, Eloise makes friends and is eager to go to school. Despite their integration into their new society, there remains a sense of sadness around father and daughter. In one of the spreads, Eloisa sadly looks out at the rain and her father stares at the photograph of a woman. This suggests that the woman in the photograph is Eloisa's mother, who is not there with her family. The text makes no mention of her and does not reveal what has happened to her. 
In the final spread, a teacher, who may be a grown-up Eloisa, is surrounded by a group of children and one insect, and it becomes clear that it is she who has been narrating the story. The book's endpapers provide further clues to Eloisa's backstory, but there is a lingering ambiguity, since they raise the question of whether the bugs were 'real' or simply represented Eloisa's subjective perception of the people in a place she was unfamiliar with, especially as the text makes no reference to bugs.

This book offers a hopeful message that one has the ability to reconstruct one's life despite traumatic experiences of loss and migration, that one can learn to overcome initial feelings of estrangement and integrate in a new society. The picturebooks adopts a gentle, metaphorical approach to all these issues, especially the use of the bugs. While they initially appear frightening as they tower over and crowd around Eloisa, the warmth of the pastel tones in the illustrations and the creatures' big eyes and rounded shapes suggest they are more curious than hostile. In addition, they look after one another and help the father and daughter find their way. The use of the bugs allows a meditation on feelings of being different and the effect of the subjective perceptions of those around us, including their potential to cause fear, prejudice, and exclusion.

As Eloisa realises that common human activities bind all communities and receives or engages in acts of kindness and friendship, her feeling of being increasingly at home is reflected in the images. While she is first seen as small, compared to the creatures, as the story progresses she appears larger, until the last spread where her figure dominates the classroom. Next to her is a smallish insect figure, suggesting that it is a newcomer, an 'outsider', that others may now need to support. While Eloisa becomes more integrated in her new community, the picturebook subtly suggests that this does not mean abandoning the past as her identity continues to be constructed by the photographs that contain her memories.

Eloisa y los Bichos is often recommended by Spanish and Latin American children's literature specialists to discuss issues around migration and integration. One of the Mexican mediators who lives on the border with the United States and has worked with migrants regularly uses this book and gifts it to families. She says when they read the book, they speak about 'what they [like Eloisa and her father] had left along the road [ $\ldots$ and the] people they had met when they arrived here, like the little "bicho" who gifts [Eloisa] the apple'. These conversations then turn to practical ways of bringing about hope.

\subsection{Footpath Flowers}

Footpath Flowers is a wordless picturebooks that portrays a little girl walking home through the city with her father. At the start of the story, the girl's surroundings are illustrated in monochrome, with the exception of the girl's bright red coat. As she goes on her journey, she starts collecting flowers, which are shown in colour. Each time she picks a flower, looks at, or touches something, more objects come into colour as do more of her surroundings, until she arrives at her house, which is all colourful. Here, we meet her extended family (mother and two brothers) before she moves on through and into the last double spread, where the perspective changes and we see her from behind as she walks all alone through a colourful field of flowers with many birds.

The perspective of the reader is at the girl's level, and sometimes we only see headless passers-by. Other people, whether those walking in the street or her dad, pay little attention to her, and they, for the most part, appear unhappy and bored. Unlike them, she is highly engaged in her surroundings, often seeing what the human adults are not able to and connecting in a meaningful manner with non-human beings, whether plants or animals.

While it may not necessarily be its primary theme, hope is a running thread throughout the book and manifests in a variety of ways. To begin with, it is in the girl's sense of purpose and forward motion and the book's message of continuation as the girl's journey extends beyond the end of the story. More crucially, hope becomes a disposition of openness to the world and the exercise of one's agency to explore possibilities of engagement with the environment through the acts of kindness and gift-giving observed through the gift-giving of flowers, which transform the world around her. Finally, the book also acknowledges the importance of home and homemaking, which perhaps anchors the girl's openness. As the girl gets closer to home, the increasingly familiar world around her grows more colourful. 
The book has been used by mediators who are involved with Albergue Las Memorias, a community that fosters community-building and empowerment in Tijuana, Mexico. Most of those participating in the cultural and literacy activities are not young people, but LGBT adults who may sometimes also share a history of being migrants themselves. The reading of this book led to a wide variety of responses. Perhaps not surprisingly, the feeling of nostalgia was common to many of these responses, with many remembering stories of their youth and of other times in their lives when they moved from one place, one city, or one country to another. There were also many remembered feelings of joy and surprise. As one mediator said, 'The memories in our heart are many and varied, and it is well worth the effort to remember and to once again be inspired by them'.

\subsection{The Arrival}

At the start of The Arrival, the nameless central character, a man, finds himself within a context where he is unable to maintain the safety and well-being of his family. He decides to travel to a strange city via boat. He arrives with nothing more than a suitcase and has to find shelter, food, and work. At the same time, he has to negotiate his way through and around the barriers caused by vast cultural and linguistic differences. He survives his journey and thrives, thanks to acts of kindness by understanding empathetic strangers whom he meets through a series of subplots. The Arrival is a wordless graphic novel, with images presented in tones of sepia and grey. The illustrations also include steampunk/futuristic and surreal elements, such as an invented language and strange animal companions, which works effectively to disorientate and then orientate the viewer.

In Tan's own words, The Arrival was intended as a universal migrant story, a distillation of 'multiple anecdotal histories' into a single story [32] (p.96). On the back cover of the book, he writes:

What drives so many to leave everything behind and journey alone to a mysterious country, a place without family or friends where everything is nameless and the future is unknown? This silent graphic novel is the story of every migrant, every refugee, every displaced person, and a tribute to all those who have made the journey [33].

Tan believes that prejudice, fundamentalism, and oppression have arisen from a rejection of values such as empathy, curiosity, and imagination, and it is his intention to harness design principles that create a need for viewers to foster critical literacies and enter into a process of questioning [32] (p. 394).

Throughout the book, Tan demonstrates that forging new relationships and friendships is key in helping migrants negotiate the 'strangeness' of their daily lives in a new space/place. In one instance, while shopping for food, his central character strikes up a friendship with a man (and his son) who assist by introducing him to unfamiliar vegetables. They then extend to him an invitation to join them for a meal, where laughter, music, gift-giving, and stories of migration are shared. In another encounter, the central character finds work in a factory and meets an older man who tells his story of war, death, grief, and loss. After work, he is taken to meet his colleague's friends and joins them in a communal game.

The text presents the possibility for readers to understand the narrative as a series of intertextual mirroring opportunities related to events and actions in their own lives, as well as window-like opportunities to problem-solve alongside the characters encountered. In each workshop we ran, the cultural mediators were drawn repeatedly to Tan's The Arrival. One of the Egyptian mediators likes to use the books and ask children to respond by acting out aspects of the book. This sometimes leads the children to express their emotions and share moving personal stories connected to past traumas or present precarity.

In all five books, we observed a clear hopeful impulse, clearly evident in the orientations of the characters towards their immediate future at the end of the books. Their trajectories in the stories lean towards the maintenance of or an increase in the level of comfort in their own selves and identities, greater integration in their environments, or a reconciliation with their communities. Most importantly, these developments never require of them to abandon who they are or to completely forget where they have come from, even if the characters in some of the books face or overcome hardship. Despite his failed experiments, Amgad is undeterred in his quest; Amma Osha continues to talk, this time with 
the indulgence of her community; the girl in Footpath Flowers looks to continue her colourful journey; Eloisa and Tan's nameless character are integrated in their new locations while maintaining strong connections to their past. Each protagonist draws upon cultural, conceptual, and physical tools to direct their hopes. These are overviewed in Table 2.

\section{Discussion: Resources of Hope}

Mediators working with children in contexts of displacement and precarity constantly turned their attention to these five texts. That is perhaps not surprising, given that each picturebook is centred on characters who used the resources surrounding them to transform their immediate selves and communities. These resources of hope and the spaces where they are prominent in texts can help mediators to make choices in other contexts.

To begin with, mediators need to closely examine the textual and visual representations and identify books that contain 'textual landmarks' [34] (p. 97) that provide familiar points of navigation for readers/viewers. In Al-Amma Osha, the cultural setting of the story is developed within the images related to the characters' clothing and elements of the setting. There are also religious markers, such as mosques and Amma Osha's veil. The landmarks of place and community appear more generic in Amgad, Footpath Flowers, and Eloisa y los Bichos, providing representations of ubiquitous cities. Amgad offers opportunities to make intertextual links to local beliefs and sayings, which act as sources of humour. The Arrival is set in a strange-yet-familiar city inspired by historical depictions of real places. Tan acknowledged that he created a world that juxtaposes 'the familiar or normal with the exotic or weird' [35] (p. 22). The viewer is simultaneously disorientated and then orientated through a series of images such as the strange animal creature on the front cover, followed by the endpapers that resemble passport photographs of people from across the globe, which were 'inspired by photographs from the archives of the Ellis Island Museum in New York City' [36] (p. 12). We would suggest that these textual landmarks function as anchors that provide opportunities for readers/viewers to locate their identity and culture within a text, a necessary first step in allowing children to develop a sense of self and community, and a starting point from where hope emerges. Alternatively, they may provide a window into alternative and off-kilter worlds, and mediators need to support readers in navigating these fictional spaces.

It is significant that both Al-Amma Osha and Footpath Flowers focussed on the characters' sense of being at home in the world, relating both to a quest for self-understanding and a clearer sense of identity through engagement with family and the wider community. Then, there is a more prosaic representation of physical domestic space, which is present in all of the books in some form. In Amgad, most of Amgad's experiments take place at home with the support of his parents; Amma Osha temporarily retreats to her home where it becomes a space for recuperation after the community visit her and sing for her to continue talking. In Footpath Flowers, the girl's journey with her father leads her home before she can continue her journey. In Eloisa y los Bichos, the journey from the girl's home to the school recurs and demonstrates how her relationship to her new environment evolves. Only one spread shows the two characters in the intimacy of their home, and it is here that they seem to reach the point where new and old lives adjust to each other. Finally, there is The Arrival, where Tan brings his book towards a close with a kitchen scene that simultaneously mirrors and contrasts with an earlier kitchen scene in the opening of the book. The final kitchen scene shows the central character surrounded by everyday artefacts encountered since his arrival, placed in positions that mirror the earlier image, indicating the end of the protagonist's diasporic journey [37] (p. 54). In this manner, The Arrival hints at the notion that we are all in a state of constant arrival, drawing on resources of hope through friendships, storytelling, language, and artefacts of continuity to relocate and build our identities in an ever-changing world [38].

If hope is linked to homemaking, homemaking in these instances refers to more than the building of a physical home, namely the creation and rekindling of significant social relationships, networks [39] (p. 82), and material culture [40]. There is significance in portraying characters such as Tan's nameless protagonist engaged in 'homemaking' [41] (p. 162), repositioning themselves through 'processes of 
belonging' [42] enacted over time and space. Through a series of interactions in their communities, the protagonists draw upon the resources of hope surrounding them to transform liminal spaces into meaningful ones through the sharing of stories; physical touch; gift-giving and receiving; the sharing of food; and sociability with others. Hope for a transformative future is driven in these books by present actions and engagements with the immediate world/environment.

Mediators should also look for texts that provide safe spaces for experimentation, offering readers the ability to enter a liminal space where the future is unknown, but through the interactions of the characters they can experience different ways of making the unfamiliar more familiar, trying out new ideas and becoming more aware of the resources of hope such as friendships, people, places, and artefacts that surround them. Amgad visualises a series of failed experiments that paradoxically contribute to the lead character's healthy identity development, and the girl's offerings of flowers to various animals and people in Footpath Flowers are acts of engagement that literally add colour to the world. The increasing familiarity of the main character in The Arrival with his surroundings is a direct outcome of his own experimentation, both successful and failed, as he tries out various food items and jobs, approaches people for help, and tentatively interacts with the strange pet that he has somehow acquired along the way.

The books also show how the protagonists are able to transform the physical and mental worlds surrounding them. The girl in Footpath Flowers directly transforms her world from monochrome to colour through touch. Tan's main character in The Arrival transforms from the migrant receiving friendship and hospitality to the one whose daughter now gives direction to other migrants, the same help offered to him on his arrival. For Eloisa in Eloisa y los Bichos, she is transformed through her friendships with others and able to enter into memory work connecting her childhood, absent mother, and future self as a teacher. Amgad's experimentation enriches his search for a future career path, even if it is not yet clear, while the ending of Al-Amma Osha offers a glimpse into a more tolerant and inclusive world where no one needs to curb any parts of themselves or their mode of self-expression.

We want to emphasise that these texts prefigure ways of being in the world, providing children with thought experiments that they can draw upon to situate themselves and their communities within the world. The texts are developed around resources of hope that have the potential to propel children towards a hope in the here and now rather than some abstract future. As readers observe characters in these texts engage with resources of hope, the literature itself becomes a resource of hope, suggesting ways for readers to think and respond to their contexts of displacement and precarity. Mediators who can identify and understand the significance of textual anchors, processes of homemaking, and potential resources of hope using the suggested questions in Table 3 will be well placed to enable children to identify similar resources of hope that can be used in directing their future possibilities.

Table 3. Questions for mediators to use when identifying resources of hope.

\begin{tabular}{cl}
\hline Resource of Hope & \multicolumn{1}{c}{ Questions for Mediators } \\
\hline Textual and visual anchors & $\begin{array}{l}\text { Does the text allow the child to make connections to self, family, } \\
\text { and community through the visuals and text? }\end{array}$ \\
\hline Homemaking & $\begin{array}{l}\text { How do the texts pay attention to home? What functions does } \\
\text { the home play? Are they spaces of refuge/comfort, } \\
\text { experimentation, anchors? In which spaces do characters feel at } \\
\text { home? How does the role of home change within the story? }\end{array}$ \\
\hline Experimentation & $\begin{array}{l}\text { How do the characters get to play, try out new ideas and new } \\
\text { identities? How are they assisted in doing so? }\end{array}$ \\
\hline \multirow{2}{*}{ Transformations } & $\begin{array}{l}\text { What positive transformations take place within the story? } \\
\text { What brings about these transformations? } \\
\text { How are they encouraged and facilitated? }\end{array}$ \\
\hline Hopeful orientations & $\begin{array}{l}\text { How do the children draw upon experimentation, } \\
\text { transformation, and homemaking processes to direct their hopes? }\end{array}$ \\
\hline
\end{tabular}




\section{Conclusions}

The texts analysed above emerged from our discussions with mediators and portrayed hope as a generative, homemaking process that could enable children in contexts of vulnerability to gain direction, 'move on' through the world, and find pathways of looking into a possible future. These resources of hope transport the children's experiences from a hard-anchored present to a future of potential experiences and engagements with the world. Systematically including quality books like these as part of a cultural intervention is critical because it meets the children's needs for hope as a structural way of being in the world under precarious circumstances. The questions developed in Table 3 will allow mediators and educators working with children in a range of precarious contexts to examine a wider range of texts that can manifest hope.

Wider considerations include training for mediators, the sharing of experiences, and the establishment of spaces for vulnerable children, families, and communities to meet. Humanitarian crises require a comprehensive response that calls for shelter, protection, food, and cultural resources. This returns us to our starting point and the need to include children's literature in any post-disaster intervention with displaced children, families, and communities [43].

Author Contributions: Conceptualization, J.E.M. and S.A.G.; methodology, J.E.M. and S.A.G.; validation, formal analysis, J.E.M., S.A.G., E.A., L.H., Y.M.; writing—original draft preparation, J.E.M., S.A.G., E.A., L.H., Y.M.; writing一review and editing, J.E.M. and S.A.G. All authors have read and agreed to the published version of the manuscript.

Funding: This research was funded by the Arts and Humanities Research Council-Global Challenges Research Fund grant number [AH/R004218/1].

Acknowledgments: The authors would like to acknowledge the support and guidance of Nadia Kholy from the Egyptian Board on Books for Young People, a CLCCD network member, who was involved in creating the toolkit text selection guide and curating the texts selected for the Cairo based workshops.

Conflicts of Interest: The authors declare no conflict of interest.

\section{References}

1. International Organisation for Migration(IOM). World Migration Report; IOM UN Migration: Geneva, Switzerland, 2020.

2. United Nations Refugee Agency (UNHCR). Global Trends: Forced Displacement in 2017; UNHCR: Geneva, Switzerland, 2018; Available online: https://www.unhcr.org/5b27be547.pdf (accessed on 26 June 2019).

3. Tsourapas, G. Egypt: Migration and Diaspora Politics in an Emerging Transit Country; Migration Policy Institute: Washington, DC, USA, 2018; Available online: https://www.migrationpolicy.org/article/egypt-migrationand-diaspora-politics-emerging-transit-country (accessed on 7 September 2020).

4. Hobfoll, S.E.; Watson, P.; Bell, C.C.; Bryant, R.A.; Brymer, M.J.; Friedman, M.J.; Friedman, M.; Gersons, B.P.R.; de Jong, J.T.V.M.; Layne, C.M.; et al. Five Essential Elements of Immediate and Mid-Term Mass Trauma Intervention: Empirical Evidence. Psychiatry 2007, 70, 283-315. [CrossRef] [PubMed]

5. Arizpe, E.; Colomer, T.; Martínez-Roldán, C.; Bagelman, C.; Belloran, B.; Farrell, M.; Fittipaldi, M.; Grilli, G.; Manresa, A.M.; McAdam, J.; et al. Visual Journeys through Wordless Narratives: An International Inquiry with Immigrant Children and 'The Arrival'; Bloomsbury Academic: London, UK, 2014.

6. Short, K.G. Critical content analysis as a research methodology. In Critical Content Analysis of Children's and Young Adult Literature; Johnson, H., Mathis, J., Short, K.G., Eds.; Routledge: Oxon, UK, 2017; pp. 1-15.

7. Freire, P. Pedagogy of the Oppressed; New revised edition; Penguin: London, UK, 1996.

8. Nilsen, A.P.; Donelson, K.L. Literature for Today's Young Adults, 4th ed.; HarperCollins: New York, NY, USA, 1993.

9. Beauvais, C. The Mighty Child; John Benjamans Publishing Company: Amsterdam, The Netherlands, 2015.

10. Bloch, E. The Principle of Hope; Plaice, N., Plaice, S., Knight, P., Eds.; Basil Blackwell: London, UK, 1986.

11. Halpin, D. Hope and Education: The Role of the Utopian Imagination; RoutledgeFalmer: London, UK, 2003.

12. Freire, P. Pedagogy of Hope; Continuum: London, UK, 1994.

13. Webb, D. Paulo Freire and "the need for a kind of education in hope". Camb. J. Educ. 2010, 40, 327-339. [CrossRef]

14. Webb, D. Modes of hoping. Hist. Hum. Sci. 2007, 20, 65-83. [CrossRef] 
15. Duncan-Andrade, J.M.R. Note to educators: Hope required when growing roses in concrete. Harv. Educ. Rev. 2009, 79, 181-194. [CrossRef]

16. Paterson, K. The Invisible Child: On Reading and Writing Books for Children; Dutton Children's Books: New York, NY, USA, 2001.

17. Levitas, R. The Concept of Utopia, 2nd ed.; Peter Lang: Oxford, UK, 2011.

18. Sargent, L.T. Afterword. In Utopian and Dystopian Writing for Children and Young Adults; Hintz, C., Ostry, E., Eds.; Routledge: London, UK, 2003; pp. 232-234.

19. Arizpe, E.; Farrell, M.; McAdam, J. Opening the classroom door to children's literature: A review of research. In International Handbook of Research in Children's Literacy, Learning and Culture; Hall, K., Cremin, T., Comber, B., Moll, L., Eds.; Wiley Blackwell: London, UK, 2013; pp. 241-257.

20. Smith-D'Arezzo, W.M. Diversity in children's literature: Not just a black and white issue. Child. Lit. Educ. 2003, 34, 75-94. [CrossRef]

21. Amour, M.J.S. Connecting children's stories to children's literature: Meeting diversity needs. Early Child. Educ. J. 2003, 31, 47-51. [CrossRef]

22. Strehle, E. Social issues: Connecting children to their world. Child. Lit. Educ. 1999, 30, 213-220. [CrossRef]

23. Cress, S.W.; Holm, D.T. Developing empathy through children's literature. Education 1998, 120, 593-597.

24. Nikolajeva, M. Picturebooks and emotional literacy. Read. Teach. 2013, 67, 249-254. [CrossRef]

25. Short, K.G. Children taking social action within global inquiries. Dragon Lode. 2011, 20, 50-59.

26. Jacobs, D. What's Hope Got to do With It? Toward a Theory of Hope and Pedagogy. JAC 2005, 25, 783-802.

27. Bishop, R.S. Mirrors, windows, and sliding glass doors. Perspectives 1990, 6, ix-xi.

28. Gopalakrishnan, A. Multicultural Children's Literature: A Critical Issues Approach; SAGE: London, UK, 2011.

29. Short, K.G. Critical Content Analysis of Visual Images. In Critical Content Analysis of Visual Images in Books for Young People; Johnson, H., Mathis, J., Short, K.G., Eds.; Routledge: Oxon, UK, 2019; pp. 3-22.

30. Williams, R. Resources of Hope: Culture, Democracy, Socialism; Verso: London, UK, 1989.

31. McAdam, J.E.; Hirsu, L.; Abou Ghaida, S. 'Why does that lighthouse have a speaker on it?': The potential of Arabic picturebooks. Engl. 4-11 2018, 63, 9-12.

32. Earle, H. Strange migrations: An essay/interview with Shaun Tan. J. Postcolon. Writ. 2016, 52, 385-398. [CrossRef]

33. Tan, S. The Arrival; Hodder Children's Books: London, UK, 2007.

34. Mackey, M. Narrative Pleasures in Young Adult Novels, Films, and Video Games; Palgrave Macmillan: Basingstoke, UK, 2011.

35. Tan, S. Strange migrations. IbbyLink 2012, 35, 22-31.

36. Tan, S. Sketches from a Nameless Land: The Art of The Arrival; Hodder: London, UK, 2010.

37. Banerjee, B. Creating a 'well-fitted habitus': Material culture, homemaking and diasporic belonging in Shaun Tan's The Arrival. J. Graph. Novels Comics. 2016, 7, 53-69. [CrossRef]

38. McAdam, J.E. Narratives of change; the role of storytelling, artefacts and children's literature in building communities of inquiry that care. Camb. J. Educ. 2019, 49, 293-307. [CrossRef]

39. Nowicka, M. Mobile locations: Construction of home in the group of transnational professionals. Glob. Netw. 2007, 7, 69-86. [CrossRef]

40. Miller, D. The Comfort of Things; Polity Press: Cambridge, UK, 2008.

41. Dowling, R.; Mee, K. Home and homemaking in contemporary Australia. Hous. Theory Soc. 2007, 24, 161-165. [CrossRef]

42. den Besten, O. Local belonging and 'geographies of emotions': Immigrant children's experience of their neighbourhoods in Paris and Berlin. Childhood 2010, 17, 181-195. [CrossRef]

43. Hirsu, L.; Arizpe, E.; McAdam, J. Cultural interventions through children's literature and arts-based practices in times of disaster: A case study of reading mediators' response to the Mexican earthquakes (September 2017). Int. J. Disaster Risk Reduct. 2020, 51, 101797. [CrossRef] [PubMed]

Publisher's Note: MDPI stays neutral with regard to jurisdictional claims in published maps and institutional affiliations. 